\title{
Intraperitoneal Barbiturate Overdose
}

\section{Euthanasia}

National Cancer Institute

\section{Source}

National Cancer Institute. Intraperitoneal Barbiturate Overdose Euthanasia. NCI

Thesaurus. Code C90400.

A method of euthanization whereby a subject is anesthetized and barbiturate(s) are

administered intraperitoneally to induce respiratory arrest. 